\title{
In vivo imaging of mice infected with bioluminescent Trypanosoma cruzi unveils novel sites of infection
}

Cristina Henriques ${ }^{1,2,3,4}$, Andréa Henriques-Pons ${ }^{5}$, Marcelo Meuser-Batista ${ }^{5,6}$, Aline Salgado Ribeiro ${ }^{5}$ and Wanderley de Souza ${ }^{1,2,3,7^{*}}$

\begin{abstract}
Background: The development of techniques that allow the imaging of animals infected with parasites expressing luciferase opens up new possibilities for following the fate of parasites in infected mammals.

Methods: D-luciferin potassium salt stock solution was prepared in phosphate-buffered saline (PBS) at $15 \mathrm{mg} / \mathrm{ml}$. To produce bioluminescence, infected and control mice received an intraperitoneal injection of luciferin stock solution $(150 \mathrm{mg} / \mathrm{kg})$. All mice were immediately anesthetized with $2 \%$ isofluorane, and after 10 minutes were imaged. Ex vivo evaluation of infected tissues and organs was evaluated in a 24-well plate in $150 \mu \mathrm{g} / \mathrm{ml}$ D-luciferin diluted in PBS. Images were captured using the IVIS Lumina image system (Xenogen). Dissected organs were also evaluated by microscopy of hematoxylin-eosin stained sections.
\end{abstract}

Results: Here we describe the results obtained using a genetically modified Dm28c strain of T. cruzi expressing the firefly luciferase to keep track of infection by bioluminescence imaging. Progression of infection was observed in vivo in $\mathrm{BALB} / \mathrm{c}$ mice at various intervals after infection with transgenic Dm28c-luc. The bioluminescent signal was immediately observed at the site of T. cruzi inoculation, and one day post infection (dpi) it was disseminated in the peritoneal cavity. A similar pattern in the cavity was observed on $7 \mathrm{dpi}$, but the bioluminescence was more intense in the terminal region of the large intestine, rectum, and gonads. On 14 and $21 \mathrm{dpi}$, bioluminescent parasites were also observed in the heart, snout, paws, hind limbs, and forelimbs. From $28 \mathrm{dpi}$ to $180 \mathrm{dpi}$ in chronically infected mice, bioluminescence declined in regions of the body but was concentrated in the gonad region. Ex vivo evaluation of dissected organs and tissues by bioluminescent imaging confirmed the in vivo bioluminescent foci. Histopathological analysis of dissected organs demonstrated parasite nests at the rectum and snout, in muscle fibers of mice infected with Dm28c-WT and with Dm28c-luc, corroborating the bioluminescent imaging.

Conclusion: Bioluminescence imaging is accurate for tracking parasites in vivo, and this methodology is important to gain a better understanding of the infection, tissue inflammation, and parasite biology regarding host cell interaction, proliferation, and parasite clearance to subpatent levels.

Keywords: Trypanosoma cruzi, Luciferase, Bioluminescence, Testicles, Rectum, Heart, Mice, Chagas disease

\footnotetext{
* Correspondence: wsouza@biof.ufrj.br

'Laboratório de Ultraestrutura Celular Hertha Meyer, Instituto de Biofísica

Carlos Chagas Filho, Universidade Federal do Rio de Janeiro, CCS-Bloco G,

Ilha do Fundão, 21941-900 Rio de Janeiro-RJ, Brazil

${ }^{2}$ Instituto Nacional de Ciência e Tecnologia em Biologia Estrutural e

Biomagens-INBEB, Janeiro-RJ, Brazil

Full list of author information is available at the end of the article
}

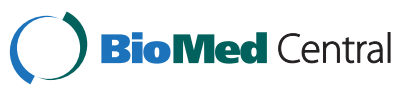

(c) 2014 Henriques et al.; licensee BioMed Central Ltd. This is an Open Access article distributed under the terms of the Creative Commons Attribution License (http://creativecommons.org/licenses/by/2.0), which permits unrestricted use, distribution, and reproduction in any medium, provided the original work is properly credited. The Creative Commons Public Domain Dedication waiver (http://creativecommons.org/publicdomain/zero/1.0/) applies to the data made available in this article, unless otherwise stated. 


\section{Background}

Trypanosoma cruzi is the etiological agent of Chagas disease, a debilitating illness that still causes 10,000 to 14,000 deaths per year and affects millions of people in Central and South America, where 8 to 10 million people are infected [1]. T. cruzi has a complex life cycle that involves the following three developmental stages: amastigote (intracellular replicative form in vertebrate host), epimastigote (extracellular replicative form found in the gut of invertebrate host), and trypomastigote (infective form for vertebrate hosts) [2]. It has been shown that T. cruzi is able to infect all nucleated mammalian cells in culture. In vivo it has been shown that even adipocytes can be infected by trypomastigotes [3]. However, cells of the reticuloendothelial, nervous and muscle systems appear to be the preferential ones in the experimental model and in $T$. cruzi-infected individuals $[4,5]$.

For a more complete understanding of the tissue distribution of $T$. cruzi in the entire animal and the evolution of the infection during the course of analysis of new anti-parasite drugs, it is important to establish experimental models in which the parasites can be easily followed within the animal. Currently available chemotherapeutic agents for Chagas disease are nifurtimox and benznidazole. Although both are active in the acute phase, their efficacy is very limited during the chronic phase. In addition, both drugs demonstrate poor activity against many $T$. cruzi isolates, and have considerable side effects that can lead to the discontinuity of the therapy [6]. In recent years, several studies attempted to identify selective metabolic targets for new drugs, making this a very active area of research. Enzymes and metabolic pathways found by proteomic, transcriptomic, and metabolomic analysis [7-9], coupled with platforms of drug design, necessitate more advanced methods of screening compounds in vivo. Novel methodologies and technologies have been developed for in vitro screening of compounds with inhibitory activity against protozoa, such as viability and proliferative assays [10]. This includes the use of transgenic parasites expressing fluorescent proteins and/or luciferase, in conjunction with sensitive imaging systems and instruments.

The bioluminescent imaging represents an innovation in pre-clinical evaluation of drugs in vivo and in the follow-up of infection in small mammals. The foci of infection can be tracked throughout the body in real time, as long as the animal is alive. This noninvasive technology gives light to the new sites of infection that could not be observed easily through histological techniques and allows investigators to evaluate the dynamic of parasite distribution in the whole body, a methodology that does not require killing the animal to evaluate infected tissues. Some studies on standardization of this important technological tool, using Trypanosoma cruzi,
Leishmania sp, and Toxoplasma gondii, have shown its application [11-14]. We previously described the use of bioluminescence imaging to follow the fate of T. cruzi in the invertebrate host [12]. In the present work, we explored, using a bioluminescent imaging system, the progression of the infection in mice infected with transgenic Dm28c-luc strain of Trypanosoma cruzi expressing luciferase. It was possible to monitor in real time the progression of infection in the same group of infected mice. This innovative technology enabled a better evaluation of the acute infection, including the discovery of tissues and organs with intense parasitism during the course of experimental infection up to the chronic phase of the disease. Bioluminescent imaging is a powerful tool for the evaluation of the effect of anti-parasite compounds on the evolution of ongoing biological processes in live mammals and other organisms.

\section{Methods}

\section{Parasites}

We used wild type Dm28c clone(Dm28c-WT) of T. cruzi and genetically modified parasites expressing luciferase (Dm28c-luc) (description below). Epimastigote forms of both strains were cultivated in liver infusion tryptose (LIT) medium supplemented with $10 \%$ fetal calf serum (FCS) at $28^{\circ} \mathrm{C}$ up to the logarithmic stage of growth [15]. Metacyclic trypomastigote forms were then obtained in vitro by subjecting $T$. cruzi epimastigotes from the late exponential growth phase (at cell density of $3 \times 10^{7}$ cells $/ \mathrm{ml}$ ) to nutritional stress in triatomine artificial urine (TAU) medium (190 mM NaCl, $8 \mathrm{mM}$ phosphate buffer, $17 \mathrm{mM}$ $\mathrm{KCl}, 2 \mathrm{mM} \mathrm{MgCl}$, $\mathrm{pH}$ 6.0) for 2 hours. Metacyclic parasites were further cultivated for five days in TAU medium supplemented with amino acids and glucose (TAU3AAG) (TAU supplemented with $0.035 \%$ sodium bicarbonate, $10 \mathrm{mM}$ L-proline, $50 \mathrm{mM}$ sodium glutamate, $2 \mathrm{mM}$ sodium L-aspartate, and $10 \mathrm{mM}$ glucose) [16]. Metacyclic parasites were used to infect LLC-MK2 cells and trypomastigote forms released from cell cultures were used to infect mice.

Intracellular amastigotes and amastigotes were obtained from LLC-MK2 cells infected with trypomastigotes and cultivated for 5 to 10 days in RPMI 1640 medium supplemented with $5 \% \mathrm{FCS}$ at $37^{\circ} \mathrm{C}$ in a $5 \% \mathrm{CO}_{2}$ atmosphere.

Dm28c-luc trypomastigotes and/or amastigotes of cell culture, maintained in culture for 5 months without G418, were differentianted back to epimastigotes after incubation in LIT medium supplemented with $10 \%$ FCS at $28^{\circ} \mathrm{C}$. Bioluminescence in epimastigotes were evaluated in a microplate reader Spectra Max2.

\section{Infection rate}

LLC-MK2 cells were plated on $13 \mathrm{~mm}$ round glass coverslips in a 24 well microplate, maintained for 18 hours in RPMI 1640 medium with $5 \% \mathrm{FBS}$ at $37^{\circ} \mathrm{C}$ in a $5 \%$ 
$\mathrm{CO}_{2}$ atmosphere. Afterwards, the cells were washed and allowed to interact with trypomastigotes of Dm28c-WT or Dm28c-luc with a parasite-host cell ratio of $10: 1$, in $200 \mu \mathrm{l}$ of $\mathrm{RPMI}$ at $37^{\circ} \mathrm{C}$ in a $5 \% \mathrm{CO}_{2}$ atmosphere. After 4 hours, cultures were washed to remove non-internalized parasites and maintained in RPMI 1640 medium with $5 \% \mathrm{FBS}$ at $37^{\circ} \mathrm{C}$ in a $5 \% \mathrm{CO}_{2}$ atmosphere for 24,48 and 72 hours. Infected cells were fixed with Bouin, washed with $70 \%$ ethanol, water and stained with Giemsa. Subsequently, coverslips were dehydrated in acetone-xylol (100\% acetone; $70 \%$ acetone - 30\% xylol; 30\% acetone$70 \%$ xylol; 100\% xylol) and sealed with Entelan (Merck). The percentage of infection and number of parasites per infected cells were quantified in at least 500 cells in a light microscope (Leica Microsystems). Two independent experiments were performed in triplicate.

\section{Animals and infection}

Seven-week-old male BALB/c mice were obtained from the Animal Laboratory Breeding Center at Fundação Oswaldo Cruz (CECAL) and housed for 7 days in the Laboratory of Cellular Ultrastructure at UFRJ under environmental and sanitation conditions established in the guide for the Care and Use of Laboratory Animals (DHEW publication No. [NIH] 80-23). This project was approved by the Biophysics Institution Committee of Ethics in Animal Research (IBCCF106), according to resolution 196/96 of the National Health Council of the Brazilian Ministry of Health. Experimental groups were composed of five mice, which were intraperitoneally infected with $1 \times 10^{6}$ or $1 \times 10^{5} \mathrm{Dm} 28 \mathrm{c}$-WT or Dm28cluc parasites in $200 \mu \mathrm{l}$ of RPMI medium. Parasitemia was determined in $5 \mu \mathrm{l}$ of blood obtained from tail snips, according to the Pizzi-Brenner method [17].

\section{Expression of firefly luciferase (Fluc) in Trypanosoma cruzi} The luciferase gene was amplified by PCR using specific primers, the forward containing an $\mathrm{XbaI}$ site and the kozak sequence upstream from the start codon (italics), 5'-GCTCTAGA GCCACC ATGGAAGACGCCAAAAA CATAAAG-3' (F-luc), and the reverse primer containing an XhoI site (italic) 5'-CCGCTCGAG CGGTTACAC GGCGATCTTTCC-3' (R-luc), using the Tli DNA Polymerase (Promega) and the following PCR conditions: $94^{\circ} \mathrm{C}, 5 \mathrm{~min} ; 94^{\circ} \mathrm{C}, 30 \mathrm{sec} ; 60^{\circ} \mathrm{C}, 30 \mathrm{sec} ; 72^{\circ} \mathrm{C}, 2 \mathrm{~min}, 30 \mathrm{cy}-$ cles; $72^{\circ} \mathrm{C}, 10 \mathrm{~min}$. The PCR product was cloned into the Zero Blunt TOPO PCR Cloning Kit (Invitrogen), digested from the TOPO vector, and subcloned into the integrative pTREX vector at the XbaI and XhoI restriction sites [18]. The construction was sequenced on an ABI 3730 Genetic Analyzer (Applied Biosystems) using the sequencing platform installed at the Oswaldo Cruz Foundation (Fiocruz).

T. cruzi epimastigote forms of Dm28c clone (Dm28cWT) were suspended at $1 \times 10^{8}$ cells $/ \mathrm{mL}$ in electroporation buffer (EPB) containing $137 \mathrm{mM} \mathrm{NaCl} ; 5 \mathrm{mM} \mathrm{KCl} 0.7 \mathrm{mM}$ $\mathrm{Na}_{2} \mathrm{HPO}_{4} ; 6 \mathrm{mM}$ glucose; $21 \mathrm{mM}$ HEPES, pH 7.3. The cellular suspension $(400 \mu \mathrm{l})$ was mixed with $50 \mu \mathrm{g}$ of plasmid, placed in a $0.2 \mathrm{~cm}$ cuvette and subjected to a pulse of $0.45 \mathrm{kV}, 500 \mu \mathrm{F}$ at room temperature in a Gene Pulser apparatus (BioRad Laboratories) [19]. The parasites were resuspended in LIT medium and stable transformants were selected with 200 to $500 \mu \mathrm{g} / \mathrm{mL}$ of G418. Thereafter, positive epimastigotes were selected by serial dilution in a 96 plate, and selected by bioluminescence emission with SteadyGlo reagent (Promega) in a SpectraMax2 microplate reader.

\section{In vitro bioluminescent imaging}

To perform a bioluminescent curve of intracellular Dm28c-luc amastigotes, LLC-MK2 cells $\left(10^{3}\right)$ were plated in a 96 well microplate and maintained for 18 hours in RPMI 1640 medium with $5 \% \mathrm{FBS}$ at $37^{\circ} \mathrm{C}$ in a $5 \% \mathrm{CO}_{2}$ atmosphere. Afterwards, the cells were washed and allowed to interact with $10^{2}$ to $10^{4}$ trypomastigotes of Dm28cluc. Infected cells were cultivated for 24 to 48 hours in RPMI 1640 medium with $5 \% \mathrm{FBS}$ at $37^{\circ} \mathrm{C}$ in a $5 \% \mathrm{CO}_{2}$ atmosphere. Bioluminescent images were obtained from trypomastigotes, and from intracellular parasites, after 24 and 48 hours of cultivation. Images were acquired after 5 minutes of incubation of trypomastigotes with $150 \mu \mathrm{g} / \mathrm{ml}$ of D-luciferin in $200 \mu \mathrm{l}$ of RPMI medium in a black 96 well microplate. Intracellular amastigotes were removed from the plate with $50 \mu \mathrm{l}$ of SteadyGlo reagent (Promega), transferred to the 96 well black microplate and the volume adjusted to $200 \mu \mathrm{l}$ of RPMI with $150 \mu \mathrm{g} / \mathrm{ml}$ of D-luciferin. Bioluminescence was quantified with automatic measurement ROI.

\section{In vivo bioluminescent imaging}

The infection with transgenic parasites was also monitored over time by detecting the bioluminescence in the whole animal using the IVIS Lumina image system (Xenogen). The equipment consists of a cooled charge-coupled camera mounted on a light-tight chamber with a nose cone delivery device to keep the mice anesthetized during image acquisition (IVIS 100; Xenogen). D-luciferin potassium salt (Xenogen) stock solution was prepared in phosphatebuffered saline (PBS) at $15 \mathrm{mg} / \mathrm{ml}$, filter-sterilized, and stored in $\mathrm{a}-80^{\circ}$ freezer. To produce bioluminescence, mice infected with Dm28c-luc and infected with Dm28c-WT received an intraperitoneal injection of D-luciferin stock solution $(150 \mathrm{mg} / \mathrm{kg})$. All mice were immediately anesthetized in an oxygen-rich induction chamber with $2 \%$ isofluorane, and images were captured after 10 minutes incubation to allow substrate distribution. Mice infected with Dm28c-WT were injected with D-luciferin (150 mg/kg) or PBS and submitted to the same procedure 
in the induction chamber, but images were acquired just after 1 hour and 24 hours post infection (1 dpi).

Bioluminescent images were obtained after 1 hour, at 1,4 to 28 , and $180 \mathrm{dpi}$ (chronic phase). Bioluminescent images were obtained of mice in dorsal, ventral, and lateral position. Anesthesia was maintained during the entire imaging process by using a nose cone isofluorane-oxygen delivery device in the light-tight chamber.

To acquire the bioluminescent images, some parameters were considered based on the level of bioluminescent emission, such as the time of exposure, which ranged from a few seconds to 5 minutes, the number of pixels, and the field of view (FOV) with automatic focus. The Living Image software automatically co-registered the luminescent images, which were taken in darkness and displayed in pseudo-colors that represent the intensity of the signal and the photographic image, generating an overlay image.

\section{Ex vivo bioluminescent imaging}

Mice infected with $1 \times 10^{5} \mathrm{Dm} 28 \mathrm{c}$-luc trypomastigote forms were euthanized at 14,21, 28, and $180 \mathrm{dpi}$ (6 months), and selected organs were excised. The bioluminescence in infected tissues and organs was evaluated in a 24-well plate or in individual plates in $150 \mu \mathrm{g} / \mathrm{ml}$ D-luciferin diluted in enough volume of PBS, to cover the tissues, $0.5 \mathrm{ml}$ for 24 well plate and 1 to $2 \mathrm{ml}$ in individual plates. Images were captured using the IVIS Lumina image system (Xenogen), after 5 minutes incubation with substrate.

\section{In vivo and ex vivo bioluminescent image quantification}

To measure photon radiance, regions of interest (ROI) were selected on the surface of the mice or the 24-well plate using the automatic ROI. Bioluminescence was measured quantitatively by the Living Image ${ }^{\circ}$ software, which gave the total flux of photons or radiance (photons/second from the surface) in each pixel, summed or integrated over the ROI area, in a square centimeter $\left(\mathrm{cm}^{2}\right)$ of the tissue. These data were multiplied by one steradian (sr). The photon radiance is displayed as the average radiance, which is the sum of the radiance from each pixel inside the ROI/number of pixels or superpixels (photons/sec/ $\mathrm{cm}^{2} / \mathrm{sr}$ ) and the standard deviation of the pixel radiance inside the ROI. Bioluminescence, acquired by the CCD camera, was quantified by the Living Image ${ }^{\circ}$ software using three types of ROI: (1) the automatic ROI measurement tool, which identifies bioluminescent emission automatically, considering a threshold of 20 to $28 \%$; (2) the average background ROI, which measures the background signal in the area specified by the user and corrects the bioluminescent emission by subtraction; and (3) the subject ROI, which identifies each animal in a image. Whenever necessary, individual bioluminescent spots (foci) were summed to get the photon radiance measurements (photons/sec/ $\mathrm{cm}^{2} / \mathrm{sr}$ ) of each region of the animal: abdomen, thorax, paws, snout, ears, and urogenital region.

In the plate, bioluminescence acquired by the $\mathrm{CCD}$ camera was obtained with two types of ROI, the automatic measurement ROI, using a threshold of $25 \%$, and the average background ROI. After subtraction of background signal, bioluminescent radiance measurements (photons $/ \mathrm{sec} / \mathrm{cm}^{2} / \mathrm{sr}$ ) of spots distributed in the organ were summed to get the total radiance measurement of each organ: heart, rectum, gonads, fat tissue, intestines, tail, ears, snout, hind limbs, and forelimbs. Thereafter, the sum of bioluminescent radiance found in the whole 24-well plate, considered $100 \%$, was used to estimate the percentage of bioluminescence in each organ.

\section{Histological analysis}

Mice infected with Dm28c-luc, with Dm28c-WT and uninfected control mice, were euthanized at the time points indicated in the figure legends to collect heart, rectum, gonads, fat tissue from gonadal depot, intestines, tail, ears, snout, hind limbs, and forelimbs to be processed as described elsewhere [20]. Briefly, fragments were fixed using Millonig-Rosman solution [21], and $5 \mu \mathrm{m}$-thick slices of paraffin-embedded samples were further processed and stained using hematoxylin-eosin (HE). To obtain different and representative regions of tissues, two $5 \mu \mathrm{m}$-thick slices in an interval of $80 \mu \mathrm{m}$ were collected per slide. Qualitative analysis of tissues was based on cellular inflammatory infiltration and parasite nests.

\section{Cytokine assays}

Blood from mice infected with Dm28c-luc, with Dm28cWT and uninfected control mice, was obtained by cardiac puncture using $3.8 \%$ sodium citrate and plasma was separated after centrifugation, $1000 \mathrm{~g} / 10$ minutes at $4^{\circ} \mathrm{C}$, for cytokine analysis by flow cytometry (BD FACSCalibur ${ }^{\text {Tix }}$ flow cytometer) using the Cytometric Array kit (FlowCytomix Mouse Th1/Th2 10plex) (eBiosciences, San Diego, CA). This is a bead-based detection system for quantitative detection of GM-CSF, IFN- $\gamma$, IL-1 $\alpha$, IL-2, IL-4, IL-5, IL-6, IL-10, IL-17, and TNF- $\alpha$. The evaluation was carried out according to manufacturer instructions. Statistical analyses were performed using the Excel software. Data from cytokine analyses of Dm28c-WT and Dm28c-luc were compared using a two-tailed unpaired $t$-test. Differences were considered significant if $p$ values were $<0.05$.

\section{Results and discussion}

\section{Longitudinal evaluation of $T$. cruzi infection in mice}

We showed in a previous publication that the genetically modified bioluminescent epimastigote forms of Dm28c-luc were stable after two years of cultivation in medium and were able to differentiate into metacyclic trypomastigote forms that infected LLC-MK2 cells in vitro. Transgenic 
trypomastigote forms of Dm28c-luc, derived from cell culture, showed stable expression for six months (the period tested) [12], allowing longitudinal evaluation of the acute and chronic phases of infected mice.

To demonstrate that luciferase expression is stable in all biological forms of transgenic parasites, Dm28c-luc trypomastigotes were allowed to differentiate back to epimastigotes. Bioluminescent emission was in the range of epimastigotes maintained in LIT medium [12], displaying $20643 \pm 1495$ relative luminescence unit (RLU), as evaluated in the microplate reader, Spectra Max2. For intracellular amastigote evaluation, we used LLC-MK2cells previously infected with $10^{2}$ to $10^{4}$ trypomastigotes. Thus, Dm28c-luc trypomastigotes and LLC-MK2 cells infected for 24 and 48 hours were evaluated for bioluminescent emission using the IVIS Lumina system (Xenogen). Bioluminescence could be significantly detected in at least $1 \times 10^{3}$ trypomastigotes and intracellular parasites could be detected in LLC-MK 2 cells infected with as few as $5 \times 10^{2}$ trypomastigotes (Figure 1A), non infected LLC-MK 2 was used as negative control. Indeed, bioluminescence in infected LLC-MK $\mathrm{MK}_{2}$ was 10 fold higher than bioluminescence in trypomastigotes used to infect LLC-MK 2 (Figure 1A). Moreover, evaluation of in vitro infection of LLC-MK cells by optical microscopy of stained cells, suggests that Dm28c-luc parasites have lower infection rates: (1) after 24 hours, 20 to $10 \%$ for Dm28c-luc and 16 to $27 \%$ for Dm28c-WT; (2) after 48 hours, 9 and 9.4\% for Dm28cluc and 10 to $18 \%$ for Dm28c-WT. But once differentiated into amastigotes, these cells retain normal proliferation, comparable to wild type parasites, which ranged from 1.1 to 1.3 amastigotes per infected cell, for Dm28c-WT and Dm28c-luc $(\mathrm{n}=2)$.

As a first step to characterize infection in mice using transgenic Dm28c-luc parasites, we compared blood parasitemia with that of mice infected with the Dm 28c-WT. As shown in Figure 1B, mice infected with the wild type strain showed a typical parasitemia curve for Dm28c, which increased up to approximately $20 \mathrm{dpi}(3.0 \pm 1.0 \times$ $10^{5}$ trypomastigotes $/ \mathrm{mL}$ ) and then gradually decreased. Parasitemia peak and magnitude is in accordance with previous publications [22,23]. However, in mice infected with Dm28c-luc trypomastigote forms we found lower levels of parasitemia (Figure 1), but those mice showed active infection with patent levels of circulating parasites at all time points. This observation indicates that the course of infection may vary between Dm28c-WT and Dm28c-luc parasites and indicates that caution may be taken in the interpretation of results obtained with transgenic parasites.

Blood cytokines evaluated on $20 \mathrm{dpi}$, showed no detectable levels of IL-1 $\alpha$, IL-2, IL-4, IL-17 (data not shown), or IL-10 (Figure 2) in mice infected with Dm28c-WT and Dm28c-luc strains of T. cruzi. Dm28c-WT strain induced low levels of IL-5, IL-6, TNF- $\alpha$, and GM-CSF, but high levels of IFN- $\gamma$ (Figure 2), when compared to uninfected control mice (data not shown). High levels of IFN- $\gamma$ have been described in the acute phase of the infection, mainly produced by NK and CD4 ${ }^{+} \mathrm{T}$ lymphocytes [24]. Interestingly, the infection with Dm28c-luc induced a different profile of cytokines, with lower levels of IFN- $\gamma$ and increased levels of IL-5 and IL-6 (Figure 2). IL-6 is an important inflammatory cytokine, while IL-5, on the other hand, is a T cell-derived cytokine that mainly promotes proliferation, activation, and differentiation of eosinophils. Indeed, the inflammatory process and hindpaw edema caused by the Dm28c-luc transgenic parasite does not reproduce the natural infection (personal communication, Julio Scharfstein). It is possible that genetic manipulation for transgenesis also affected the expression and/or immunogenicity of antigens of the parasite, which led to an altered immunological response. It would be interesting to make a cytokine kinetic analysis of the blood to evaluate the profile of infection with Dm28c-luc throughout the acute and chronic infection, but this is not the scope of the present study.

To initiate longitudinal follow-up, BALB/c mice were intraperitoneally infected with $1 \times 10^{6}$ trypomastigote forms of Dm28c-luc. The same group of animals was evaluated for a month, until the beginning of the chronic phase of disease. Before each data acquisition, groups of three animals were placed in the same position inside the IVIS lumina chamber and were imaged in ventral (Figure 3-left panels), dorsal (Figure 3-central panels), and lateral (Figure 3-right panels) position. One hour after infection, bioluminescence was observed in the peritoneal cavity, near the site of inoculation, and in the urogenital region (not shown). Twenty-four hours post inoculation (1 dpi), the abdomen displayed an increase in the bioluminescent signal as a whole (Figure 3A-left and right panels). The urogenital region showed prominent bioluminescence that was more visible in the lateral position (Figure 3A-right panel). This pattern was observed until 7 dpi (Figures 3B,C-all panels, and Figure 4A), when bioluminescence reached a peak in the urogenital and abdominal regions (Figure 3C-all panels, and Figure 4A). On $7 \mathrm{dpi}$, bioluminescence was also observed in the dorsal region and in the snout of the mice (Figure 3C-central panel). On $11 \mathrm{dpi}$, the infection had disseminated to other regions of the body, as seen via bioluminescent imaging (not shown) and its quantification (Figures 4A and B). On $14 \mathrm{dpi}$, foci of bioluminescence were found distributed in different regions of the head, including the nose and ears, and in the tail and paws (Figure 3D-all panels, Figures 4A and $\mathrm{B}$ ). Bioluminescent foci were also detected in the thorax (cardiac region) (Figures 3D and 4B). However, the abdomen displayed a decreased bioluminescent signal, which was even lower on 22 and 29 dpi (Figures 3E and F, 

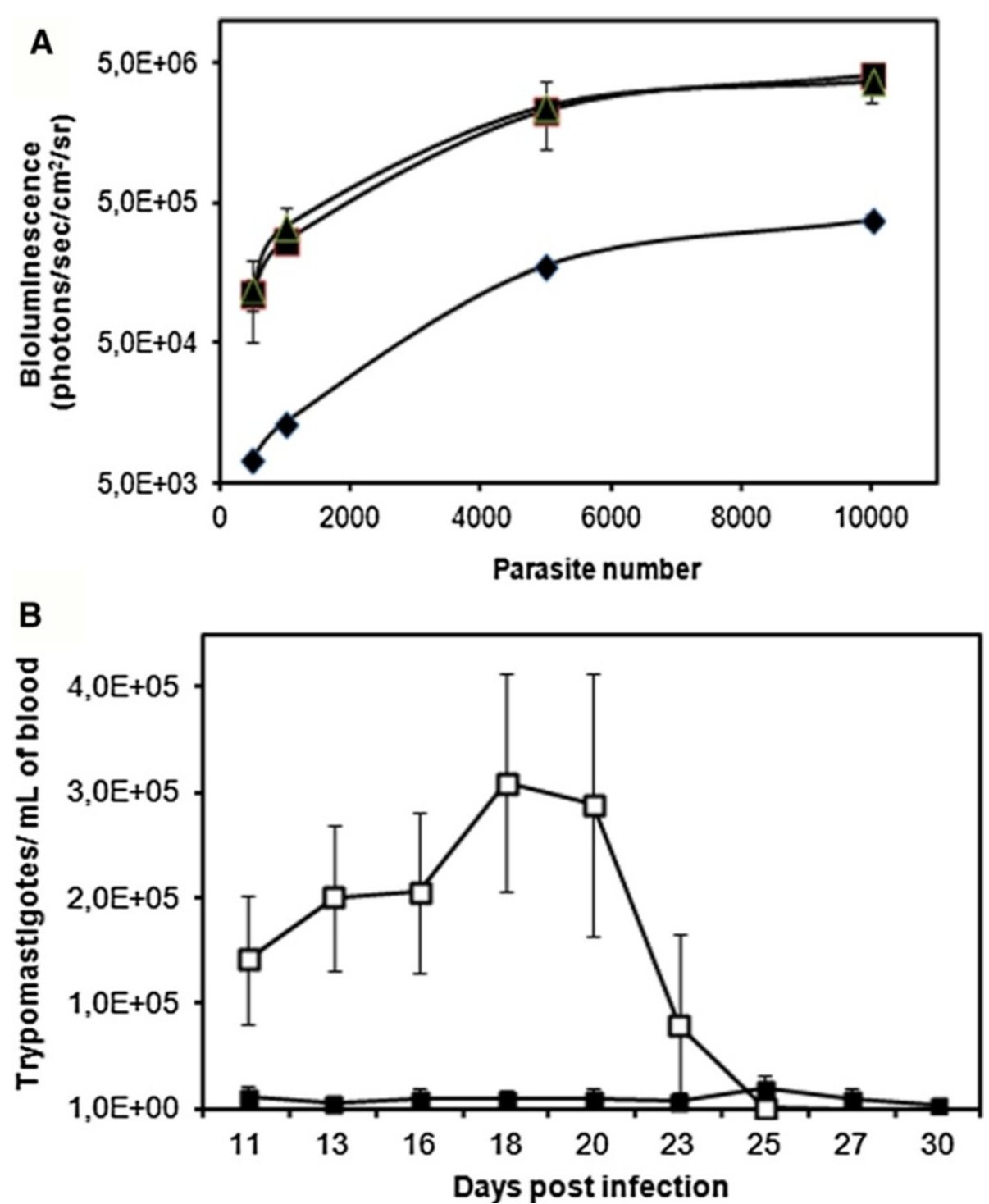

Figure 1 In vitro and in vivo parasite density curve. (A) In vitro bioluminescent measurement in the IVIS lumina system. Dm28c-luc trypomastigotes (diamond); and intracellular parasite, after 24 hours (square) and 48 hours (triangle) post infection. Three independent experiments were performed. (B) Parasitemia in mice infected with different T. cruzi populations. Animals were infected with $10^{5}$ trypomastigotes of Dm28c-WT (open squares, $\mathrm{n}=10$ ), or Dm28c-luc (solid squares, $\mathrm{n}=15$ ). Two independent experiments were performed.

Figure 4A). At $22 \mathrm{dpi}$, a peak of bioluminescence in the thorax (heart) of some mice was noticed (Figure 3 E-left panel). Around $29 \mathrm{dpi}$, bioluminescence began to decline in regions of the body and was restricted to certain foci (Figure 3F-all panels, Figure 4B) such as the urogenital region (Figure $3 \mathrm{~F}$-all panels, Figure 4A).

\section{In vivo and ex vivo evaluation of acute and chronic phases of $T$. cruzi infection}

To evaluate the development of the pathology with this new methodology, mice were also infected with a lower parasite load of $1 \times 10^{5}$ trypomastigotes of Dm28c-luc $(\mathrm{n}=20)$ or Dm28c-WT $(\mathrm{n}=20)$ strain. Each group of mice infected with Dm28c-luc was evaluated by bioluminescent imaging on $0,1,7,14,21,28$ and $180 \mathrm{dpi}$, until euthanized for ex vivo evaluation of selected organs. The same pattern of infection was observed via bioluminescence in the abdomen, with subsequent migration of trypomastigotes to the urogenital region 1 hour $(0 \mathrm{dpi})$ after inoculation (Figure 5A-all panels; Figure 6A). Twenty-four hours after infection (1 dpi), bioluminescence was disseminated into the peritoneal cavity (Figure $5 \mathrm{~B}$ ), and the urogenital region displayed a lower bioluminescent signal (Figure 6A). In some mice a punctuate site of infection, below the gonads, was observed, which in some cases corresponded to the terminal region of the rectum and portions of the large 

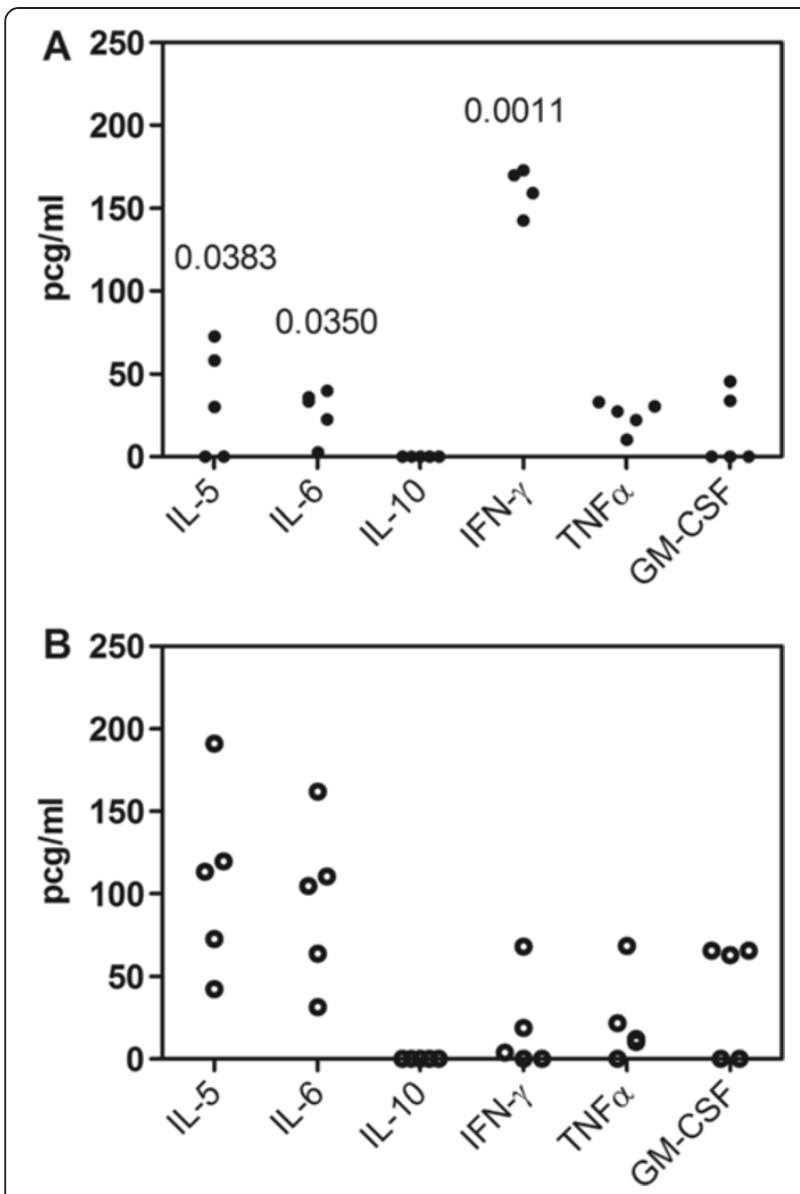

Figure 2 Analyses of cytokines in the acute phase of infection. Comparison of cytokine expression in the blood of mice infected with Dm28c-WT (A) and Dm28c-luc (B) 20 dpi. Statistically significant differences were observed for IL-5, IL-6, and IFN- $\gamma$ when the $p$ value was $<0.05$ ( $t$-test).

intestine (Figure 5B-left panel). One week after infection (7 dpi), two bioluminescent peaks were observed: (1) at the abdominal region; and (2) at the urogenital region (Figure 5C, left and right panels; Figure 6A). Some dispersed foci of infection, however, were observed in other regions of the body (Figure 6B). In the second week (14 dpi), infection was distributed to regions of the body, as evaluated by migration of bioluminescent parasites to the head, ears, paws, and tail (Figure 5D-all panels) and measurements of acquired bioluminescent signal (Figure 6B). However, the intensity of bioluminescence in the urogenital and abdominal region was reduced at $14 \mathrm{dpi}$ (Figure 6A). Considering that the diffusion of light through the tissues provides a blurred image, which prevents the precise identification of organs that are infected, we dissected groups of mice to confirm the precise location of infection. On $14 \mathrm{dpi}$ three mice were euthanized, the organs were collected and incubated with substrate D-luciferin for ex vivo evaluation in the IVIS ${ }^{\circ}$ Imaging System. Organs of each mouse were collected and grouped in one plate, bioluminescent radiance was found in the whole 24-well plate, considered as $100 \%$, this was used to estimate the percentage of bioluminescence in each organ. About $50 \%$ of bioluminescence was concentrated in the intestine, large and small intestines, and 30\% was distributed through the rectum, in the base of the tail, gonads, and fat tissue (Figure 7A; Figure 8A). We also observed $4 \%$ to $10 \%$ of bioluminescence in the snout of dissected mice (Figure 8A). In one animal we observed approximately $4 \%$ bioluminescence in the heart (Figure 8A).

In vivo evaluation on the third week (21 dpi) demonstrated that bioluminescence was reduced in the thorax, snout, ears, paws, and abdomen (Figure 5E-all panels; Figures $6 \mathrm{~A}$ and $\mathrm{B}$ ), but the urogenital region displayed stable bioluminescence (Figure 6A). Ex vivo evaluation of infected organs by bioluminescent imaging demonstrated that the colon, cecum, and rectum displayed patches of bioluminescence that corresponded to $60 \%$ of bioluminescence found in the organs investigated in the plate (Figure 7B; Figure 8B), followed by the testicles and tail, which displayed $20 \%$ of bioluminescent emission; the heart showed 3\% (Figure 8B). On the fourth week (28 dpi) post inoculation, bioluminescence declined overall in the body (Figure 5F-all panels, Figure 6A). Ex vivo evaluation revealed that infection was mainly distributed along the intestines and rectum, followed by the gonads and tail (Figure 7C, Figure 8C). Chronically infected mice, $180 \mathrm{dpi}$, displayed some foci of infection in the urogenital region, which could be quantified (Figure 6A and Figure 7E-all panels). To show that bioluminescent emission is directly related to mice infected with Dm28cluc, images of mice infected with Dm28c-WT were included as negative control (Figure 7F). Ex vivo evaluation of dissected mice corroborated that bioluminescence was predominant in the intestine, followed by the rectum and tail (Figure 7D, Figure 8D). In other organs, such as the heart, bioluminescence was undetected. Therefore, the ex vivo evaluation supports the analysis made in vivo and shows the precise sites of infection in the urogenital region. The same profile of infection, with distribution of bioluminescent parasites for some regions of the body and its containment to the urogenital region, was observed in BALB/c and Swiss mice (data not shown).

\section{Genetically modified Dm28c-luc versus Dm28c-WT strain}

After ex vivo evaluation of dissected organs by bioluminescent imaging, the tissues were embedded in paraffin, stained with hematoxylin and eosin, and observed under light microscopy (Figure 9). It was possible to observe the pattern of Dm28c-luc and Dm28c-WT migration, supporting the bioluminescent imaging and demonstrating the presence of amastigote nests in the terminal region of the intestine (Figure 9B-H). Amastigote nests were observed 


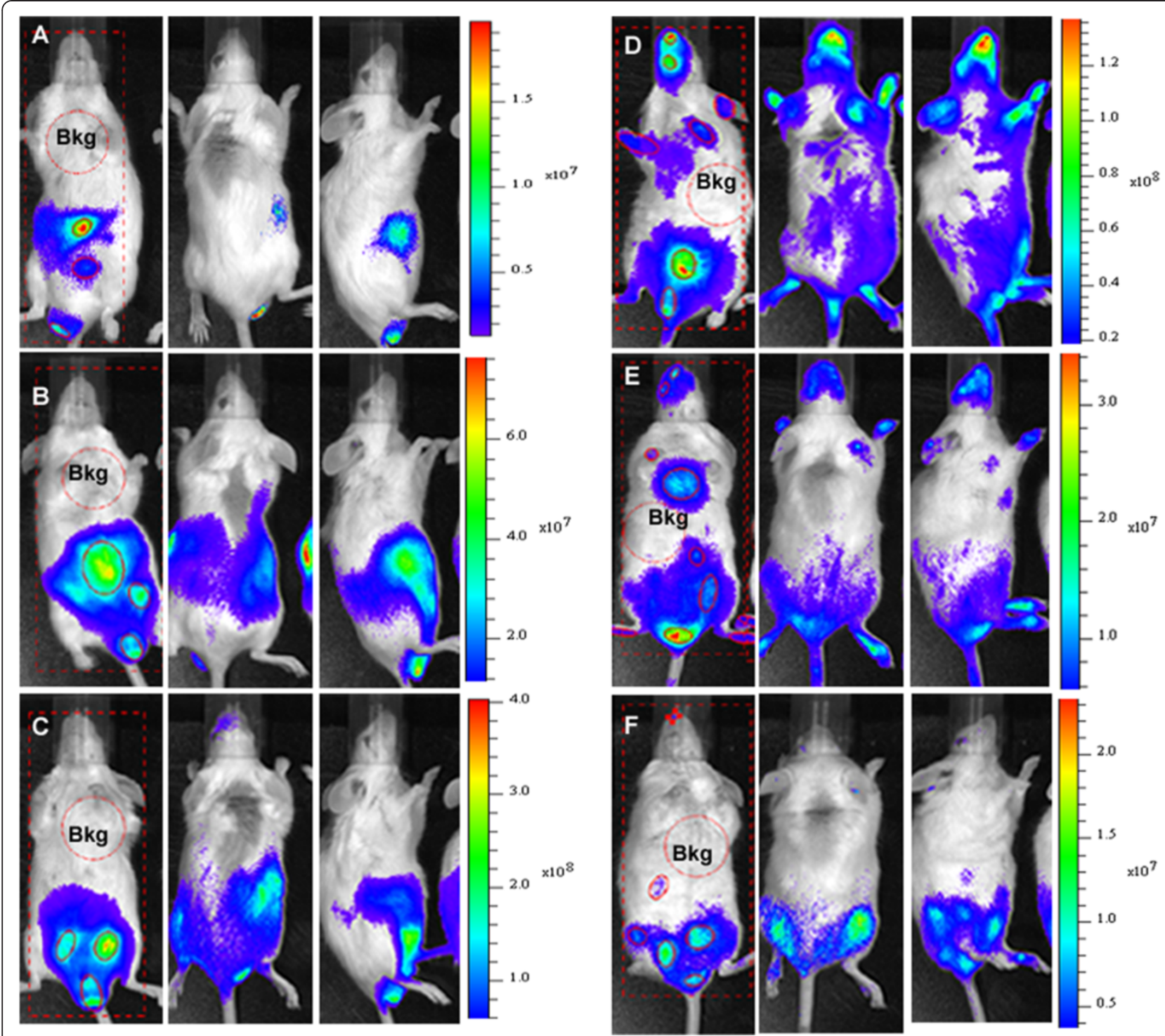

Figure 3 Follow-up of BALB/c mice infected with $10^{6}$ trypomastigotes of transgenic Dm28c-luc strain. Bioluminescent images were acquired for the same group of mice and one mouse is shown in the ventral (left panel), dorsal (central panel), and lateral (left panel) position after 10 minutes of D-luciferin injection. The same mouse was evaluated after $1 \mathrm{dpi}$ (A); $4 \mathrm{dpi}$ (B), $7 \mathrm{dpi}$ (C), $14 \mathrm{dpi}$ (D), $22 \mathrm{dpi}$ (E), $29 \mathrm{dpi}$ (F). The settings were binning small (small pixels), 10 seconds exposure. For bioluminescent signal quantification, images of mice in the ventral position were evaluated. Subject ROI (square) was used to identify each individual in the image, average background ROI (circle, red dots) measured the background bioluminescent signal which was used to correct the signal in the automatic measurement ROI (red line, circles). Scale bar of bioluminescent image radiance (photons $/ \mathrm{sec} / \mathrm{cm}^{2} / \mathrm{sr}$ ) of mouse in ventral position.

mainly in the anal region of mice infected with both strains, Dm28c-WT or Dm28c-luc (Figure 9B-H). However, oversized amastigote nests were observed on 14 $\mathrm{dpi}$ in the rectum and anal region of mice infected with Dm28c-WT (Figure 9F) as compared to Dm28c-luc (Figure 9B-C). From 21 to $28 \mathrm{dpi}$, the nests observed in the terminal region of the intestine of mice infected with Dm28c-WT decreased in size and in number of parasites (Figure 9G-H). However, with Dm28c-luc parasites, amastigote nests were more evident on the $28 \mathrm{dpi}$, which suggest a delay in the development of infection in the rectum and anal region of mice infected with Dm28c-luc (Figure 9D-E). We also observed inflammatory foci in close proximity to parasite nests in the tissues infected with both strains, Dm28c-luc (Figure 9B) or Dm28c-WT (Figure 9F). However, regions of intense lymphocyte infiltrate were observed mostly in mice infected with Dm28cWT (Figure 9F-H). As described previously, myenteric denervation has been observed in the acute phase of $T$. cruzi infection. It seems that the mechanism involves IFN $\gamma$, iNOS activation in the inflammatory foci in the intestine, and NO production [25]. Therefore, in the 

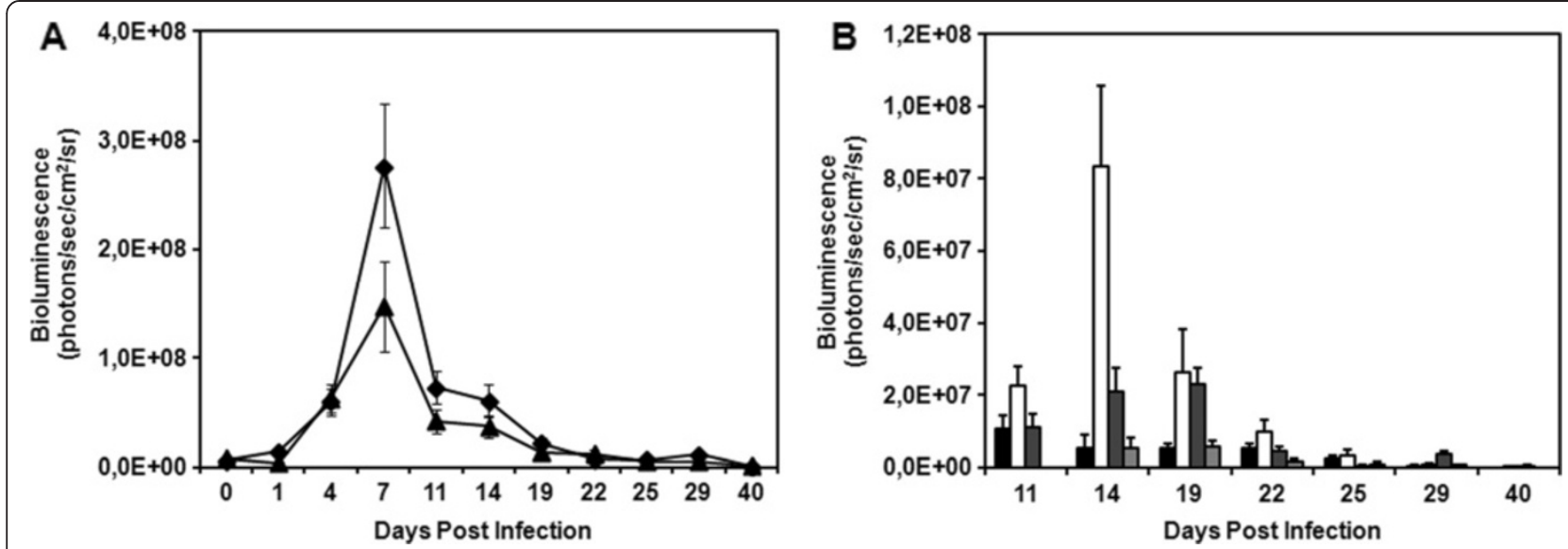

Figure 4 Follow up of BALB/c mice infected with $10^{6}$ trypomastigotes of transgenic Dm28c-luc strain. In vivo quantification of bioluminescent foci were performed in images of mice in the ventral position after subtracting the background signal from measurement ROI, identified in the images by the automatic ROI tool $(n=5)$. Average and standard deviation of radiance, in the abdomen (diamond) and urogenital region (triangle) (A), thorax (black square), snout (white square), paws (dark gray square), and ears (gray square) (B).

infection with transgenic Dm28c-luc, the reduced levels of IFN $\gamma$ and lymphocyte infiltrate could reflect a less deleterious effect in the colon and rectum.

Independent of strain tropism, previous publications demonstrated a decline in intestinal mobility, evaluated by charcoal elimination, in mice infected with different T. cruzi strains, such as Dm28c, CL-Brener, Brazil, and TcY. In the same work, it was demonstrated that Dm28c interferes with intestinal mobility earlier than do other strains, in the first week of infection [22].

In our study, the alterations observed in tissues of rectum and anal sphincter are compatible with an inflammatory process that could lead to disruption of the nervous system; however, other tissues, glands, and regions of the intestine (not investigated) could also be sites of infection, as observed with naturally infected Opossum [26]. Thus, the novel foci of infection in the acute and chronic phases, such as (a) the rectum, (b) the anal sphincter, (c) the testicle and its associated adipocyte tissues, and (d) the base of the tail, could also have an impact in the maintenance of infection in sylvatic, peri-domestic, and domestic cycle and in the transmission of the disease by routes not explored previously. In the case of Opossum, contamination of environment and food with parasites from the anal gland region has been shown [26]. Adipose tissue was described as playing a role as a reservoir for recrudescence of infection [5].

Considering that the heart is one of the most studied and affected organ by T.cruzi infection, we performed also an ex vivo evaluation of the heart by bioluminescent imaging coupled to histological analysis, and compared the myocardium infection caused by Dm28c-WT and Dm28c-luc. In mice infected with Dm28-luc, bioluminescent emission could be detected until 28 dpi with a peak at $14 \mathrm{dpi}$, and by histological analysis a few amastigote nests and scattered inflammatory cell infiltrates could be observed at 14 dpi (Figure 9I and J). However, in mice infected with Dm28c-WT, heart tissues showed more amastigote nests and a few inflammatory infiltrates (Figure 9L). In the third week after infection (21 dpi), a few and small inflammatory infiltrates dispersed in the cardiac fiber of mice infected with Dm28c-luc were observed, some of them with amastigotes (Figure 9K). However, in mice infected with Dm28c-WT a few but clearly defined amastigote nests and inflammatory infiltrate were observed (Figure 9M). At 28 dpi no amastigote nest and inflammatory infiltrate was found, only discrete and scattered inflammatory cells were observed in mice infected with Dm28c-WT or Dm28c-luc (Figure 9N).

In the murine model, previous studies have demonstrated the evolution of experimental T. cruzi infection in heart tissues, with the presence of extracellular matrix components and inflammatory infiltrate in the myocardium, caused by Y strain in the acute phase of the disease. In opposition, infection caused by Dm28c strain failed to display inflammatory infiltrate and showed rare amastigote nests [23], which suggested that different strains could display different heart tissue responses $[27,28]$.

In order to find other sites of parasite reservoirs and infection, we evaluated tissues from the snout region such as the cheeks and nose of infected mice by histopathology analysis. In accordance with bioluminescent imaging, on $14 \mathrm{dpi}$, parasite nests were also observed in the snout, in muscle fibers of mice infected with each strain, Dm28c-WT (Figure 9O) or with Dm28c-luc (Figure 9P). Considering the organization of the tissue, which was composed of collagen and connective tissues, it was more difficult to evaluate the size of nests and to find parasite nests on 21 and $28 \mathrm{dpi}$. It is important to point out that in spite of the small size of amastigote nests in the muscle 

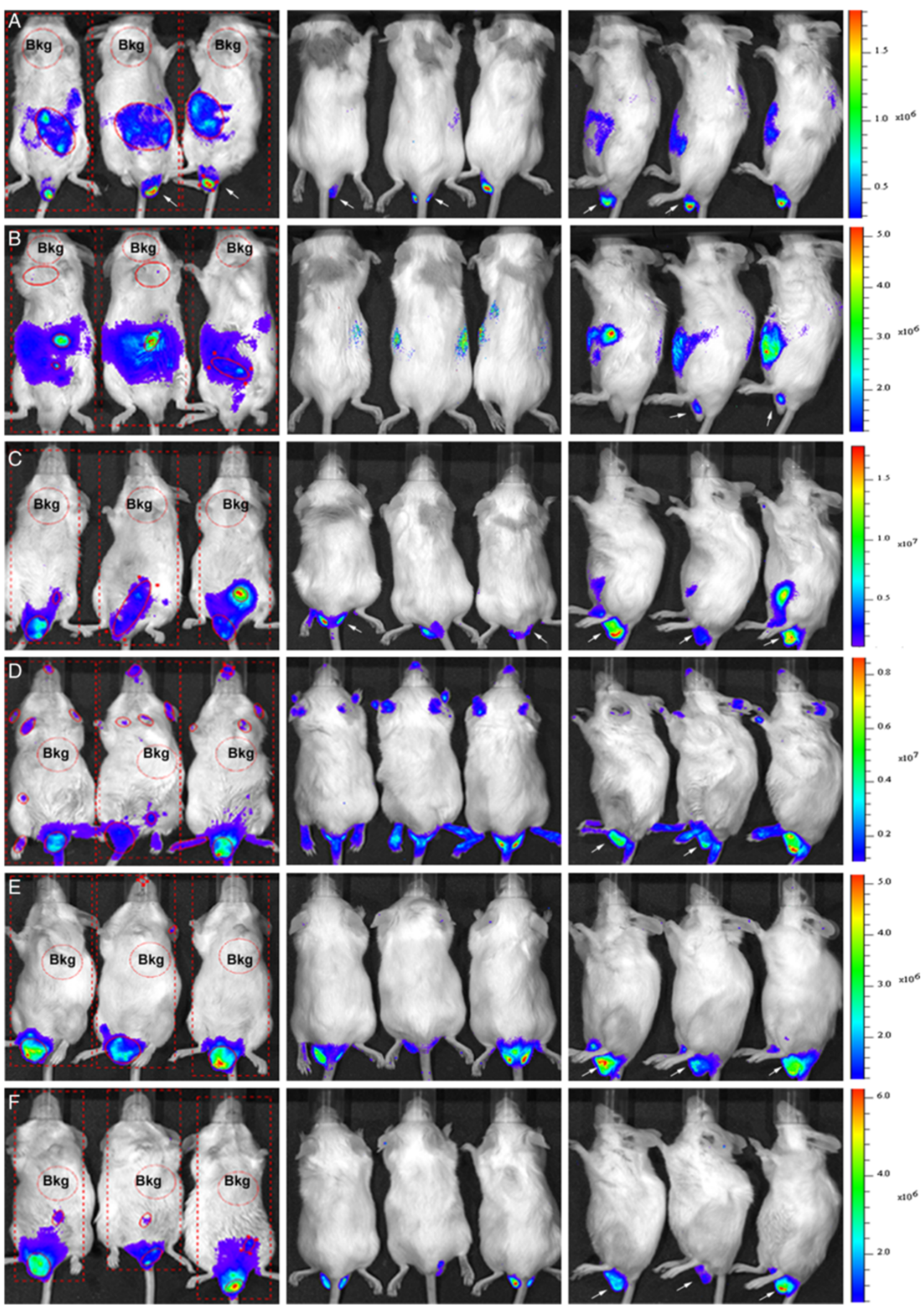

Figure $\mathbf{5}$ (See legend on next page.) 
(See figure on previous page.)

Figure 5 Follow-up of BALB/c mice infected with $10^{5}$ trypomastigotes of transgenic Dm28c-luc strain. Bioluminescent images were acquired for the same group of mice, three mice are shown in the ventral (left panel), dorsal (central panel), and lateral (left panel) position after 10 minutes of D-luciferin inoculation. The same three mice were evaluated one hour post infection $0 \mathrm{dpi}$ (A); $1 \mathrm{dpi}$ (B), $7 \mathrm{dpi}$ (C), $14 \mathrm{dpi}$ (D), 21 dpi (E), 28 dpi (F). The settings were binning medium (medium size pixels), 1 minute exposure. For bioluminescent quantification images of mice in the ventral position were evaluated. Subject ROI (square) was used to identify each individual in the image, average background ROI (circle, red dots) measured the background bioluminescent signal which was used to correct the signal in the automatic measurement ROI (red line, circles). Arrows indicate urogenital region. Scale bar of bioluminescent image radiance (photons/ $\mathrm{sec} / \mathrm{cm}^{2} / \mathrm{sr}$ ) of mice in ventral position.

fibers of the snout, bioluminescent emission was above the threshold and displayed enough photons to be captured and quantified, which confirms that firefly luciferase expression in Dm28c-luc is stable and suitable for bioluminescent image studies.

Although amastigote nests were considerably more frequent in animals infected with Dm28c-WT, the Dm28c-luc strain was able to infect mice and displayed the same pattern of infection. In vivo and ex vivo bioluminescent imaging associated with histological analyses of tissue sections corroborated that amastigote nests were larger and more frequent in the rectum and anal region, if compared to the nests found in the heart and other tissues, and these sites of infection remained during the chronic phase.

Another aspect that should be considered about bioluminescent imaging is that the methodology is able to identify even small foci of infection in the organ, but depending on the level of luciferase expression and the tissues infected, the bioluminescent signal can be under the detection limit. Due to the limitations of histological techniques to evaluate residual and small foci of infections in tissues and organs, additional techniques such as PCR and qPCR should be considered to evaluate the presence of parasites in tissues and correlate bioluminescent image with parasite burden.

Previous work has shown the use of bioluminescent imaging in vivo to follow the parasite expressing firefly luciferase within their mammalian host [29], and developed a high-throughput bioluminescent imaging assay for drug trials in mice inoculated with T. cruzi in the hind footpads [30]. It was observed that the progression of infection in mice infected with CL strain by intra peritoneal inoculation was similar to our study, displaying a peak at 10 to $14 \mathrm{dpi}$, but ex vivo bioluminescent imaging was restricted to a few organs [29]. Thus, we performed longitudinal evaluation with quantification of bioluminescent foci in vivo coupled to a detailed ex vivo analyses of several regions and organs until the chronic stage of infection, $180 \mathrm{dpi}$. Our study gives new information and insights about the progression and distribution of infection throughout tissues and foci that are not usually explored but are important sites of infection, and should be considered in studies with murine models. If this pattern of infection is also related to the strain Dm28c or to the site of inoculation, it is the scope of our next work.

The biological and genetic variability of $T$. cruzi has led to its classification into six groups or discrete typing
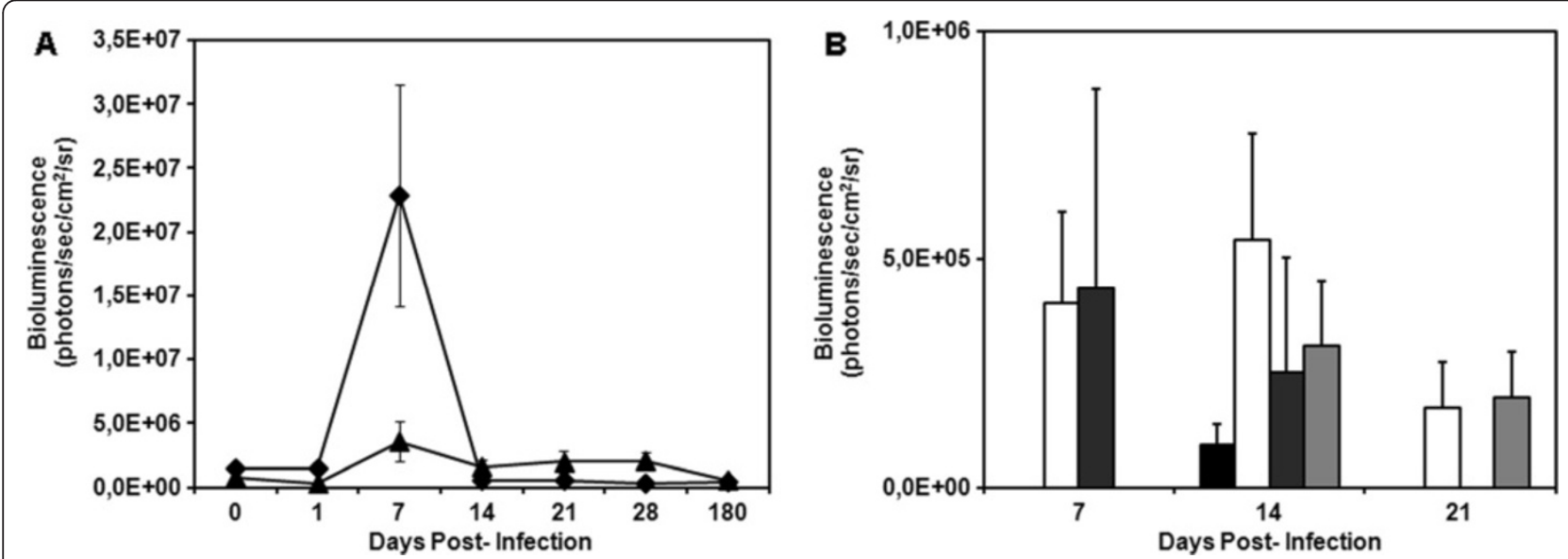

Figure 6 Follow up of BALB/c mice infected with $10^{5}$ trypomastigotes of transgenic Dm28c-luc strain. In vivo quantification of bioluminescent foci were performed in images of mice in the ventral position after subtracting the background signal from measurement ROI, identified in the images by the automatic ROI tool $(n=12)$. Average and standard deviation of radiance of abdomen (diamond) and urogenital region (triangle) $\mathbf{( A )}$, thorax (black square), snout (white square), paws (dark gray square) and ears (gray square) (B). Dpi 0 corresponds to measurements made 1 hour after inoculation. 


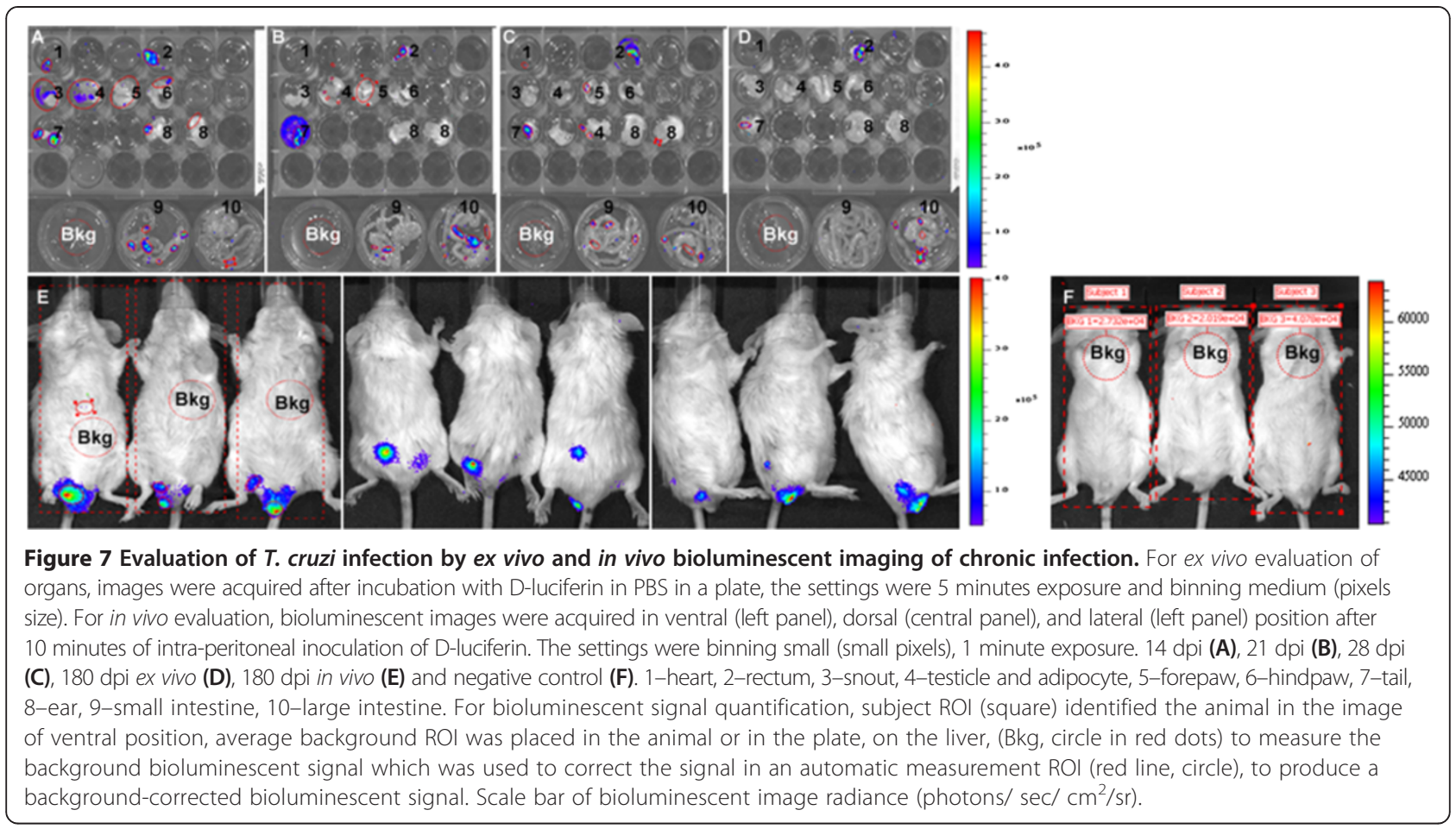

units (DTU) [31,32]. In this context, Dm28c is classified as TcI; this strain was isolated from Didelphis marsupialis in Venezuela, and the TcI genotype is widespread in Colombia, Venezuela, and Central America, displaying emerging importance [33,34]. Genotype analysis of isolates from chagasic patients, domestic and wild mammals, and triatomine bugs in Venezuela demonstrated that this group of T. cruzi accounted for most of the isolates [35]. However, the distribution of infection throughout the new foci of infection such as, (a) the rectum, (b) the anal sphincter, (c)
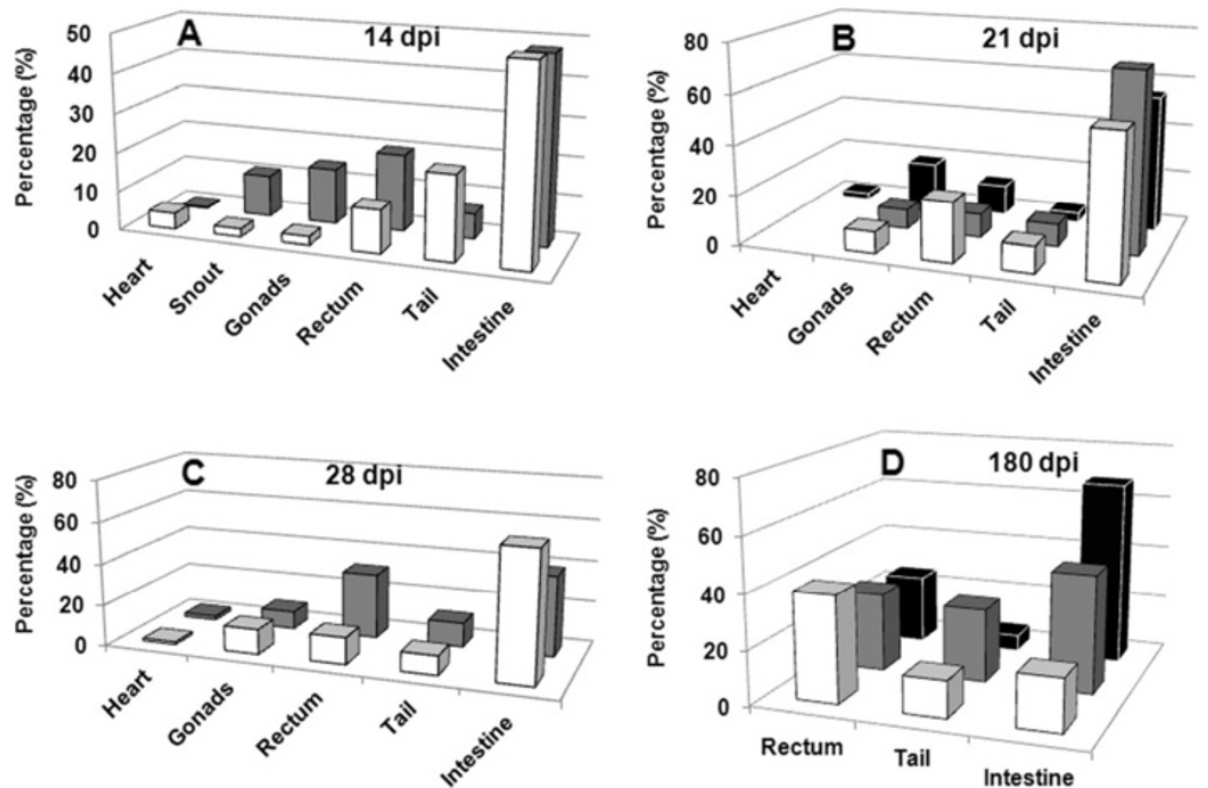

Figure 8 Follow-up of BALB/c mice infected with $10^{5}$ trypomastigotes of transgenic Dm28c-luc strain. Ex vivo quantification of bioluminescent foci, identified in dissected organs in the plate, after subtracting the background signal (liver) from measurement ROI, identified in the images by the automatic ROI tool. Heart, snout, gonads,rectum, tail, and intestine. 14 dpi (A); 21 dpi (B), 28 dpi (C), and 180dpi (D). Mice 1 (white square), mice 2 (gray square), mice 3 (black square). Percentage of bioluminescent radiance in each organ is related to total bioluminescent radiance found in the whole 24-well plate. 


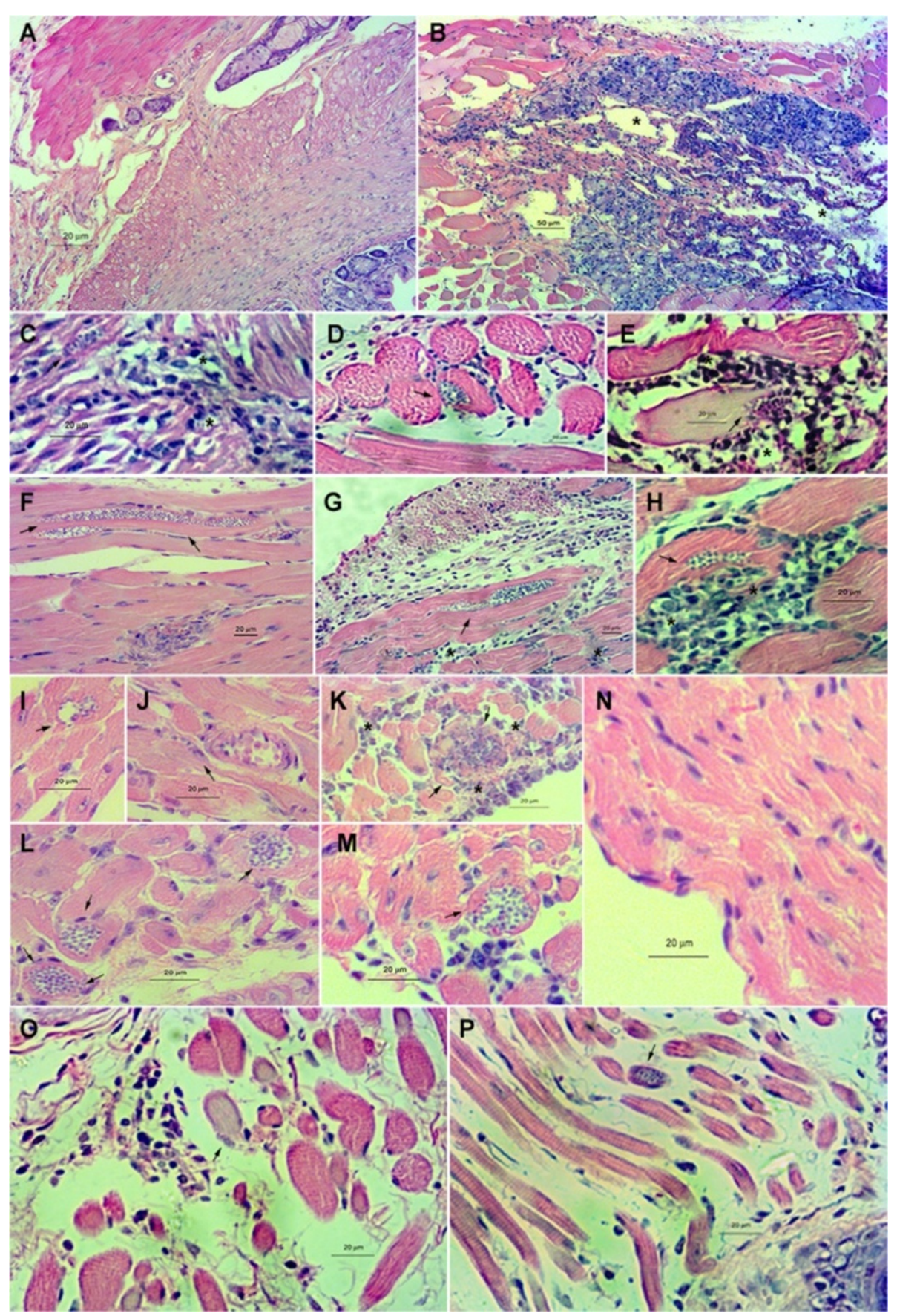

Figure 9 Parasite localization in tissues of infected animals. Ex vivo evaluation of amastigote nests in the rectum and anal region (A-H), heart (I-N) and in the snout (O-P) in BALB/c mice infected with $10^{5}$ trypomastigotes of Dm28c-luc or Dm28c-WT. Rectum of uninfected mice, control (A). Rectum of mice infected with transgenic Dm28c-luc stain (B-E): 14 dpi (B-C), 21 dpi (D), 28 dpi (E). Rectum of mice infected with Dm28c-WT strain (F-H): 14 dpi (F), 21 dpi (G), 28 dpi (H). Heart of mice infected with transgenic Dm28c-luc stain (I-K and N): 14 dpi (I-J), 21 dpi (K) 28 dpi (N). Heart of mice infected with Dm28c-WT (L-M): 14 dpi (L) and 21 dpi (M). Snout of mice infected with transgenic Dm28c-luc (O) and Dm28c-WT strain (P). Arrows indicate amastigote nests and asterisks inflammatory infiltrate.

testicles and (d) its fat tissues, is usually not evaluated in the population affected by Chagas disease and during treatment, but can have a role in disease prognosis.

\section{Conclusion}

The present work demonstrated that bioluminescent imaging associated with microscopic examination of tissue 
sections is a powerful technology that can be used for evaluation of infection in the murine model.

The genetically modified strain is stable, and suitable for follow-up studies in vivo in the murine model, whose intensity of bioluminescent emission increases in accordance with the inoculum used to infect $-10^{6}$ (Figures 3A and $\mathrm{B}$ ) or $10^{5}$ (Figures $5 \mathrm{~A}$ and $\mathrm{B}$ ). The fact that the transgenic strain could be less lethal, but able to evolve into the chronic phase for 6 months to one year (not shown), can be an advantage for drug trials in vivo. This methodology brought, for the first time, new information about the progression and dynamics of infection, detecting new sites of infection.

\section{Competing interests}

The authors declare that they do not have any competing interests.

\section{Authors' contributions}

The author WS idealized the project, contributed to the experimental design and manuscript preparation. $\mathrm{CH}$ produced the strain, executed bioluminescent imaging, data analysis and manuscript elaboration. AHP performed cytokine analysis and the result interpretation, contributed with histopathology analysis. $\mathrm{MMB}$ and $\mathrm{AS}$ performed histological techniques and analysis and contributed with the manuscript. All authors read and approved the final version of the manuscript.

\section{Acknowledgments}

We are grateful to Cynthia M. Cascabulho, from Instituto Oswaldo Cruz- IOC/ FIOCRUZ - Plataforma de Citometria de Fluxo, and Heliomar P. Marcos from Hospital Universitário Clementino Fraga Filho-HUCFF/UFR, for their assistance with flow cytometry and histological techniques. This work has been supported by Conselho Nacional de Desenvolvimento Científico e Tecnológico, Financiadora de Estudos e Projetos (FINEP), Fundação de Aperfeiçoamento de pessoal de Nível Superior, and Fundação Carlos Chagas Filho de Amaparo à Pesquisa Científica do Estado do Rio de Janeiro (FAPERJ).

\section{Author details}

'Laboratório de Ultraestrutura Celular Hertha Meyer, Instituto de Biofísica Carlos Chagas Filho, Universidade Federal do Rio de Janeiro, CCS-Bloco G, Ilha do Fundão, 21941-900 Rio de Janeiro-RJ, Brazil. ${ }^{2}$ Instituto Nacional de Ciência e Tecnologia em Biologia Estrutural e Biomagens-INBEB, Janeiro-RJ, Brazil. ${ }^{3}$ Nucleo de Biologia Estrutural e Biomagens, Universidade Federal do Rio de Janeiro-CENABIO, Janeiro-RJ, Brazil. ${ }^{4}$ Fundação Oswaldo Cruz, CruzFIOCRUZ, Mato Grosso do Sul, Campo Grande-MS, Brazil. ${ }^{5}$ Laboratório de Inovações em Terapias, Ensino e Bioprodutos, Instituto Oswaldo Cruz-Fundação Oswaldo Cruz, Janeiro-RJ, Brazil. ${ }^{6}$ Departamento de Anatomia Patológica e Citopatologia, Instituto Fernandes Figueira-FIOCRUZ, Janeiro-RJ, Brazil. Instituto Nacional de Metrologia, Qualidade e Tecnologia-Inmetro, Janeiro-RJ, Brazil.

Received: 20 September 2013 Accepted: 21 February 2014 Published: 3 March 2014

\section{References}

1. World Health Organization: Working to Overcome the Global Impact of Neglected Tropical Diseases: First WHO Report on Neglected Tropical Diseases. Geneva: World Health Organization; 2010. WHO/HTM/NTD/2010.1.

2. De Souza W, Carvalho TMU, Barrias ES: Review on Trypanosoma cruzi: host cell interaction. Int J Cell Biol 2010, 2010:295394. doi: 10.1155/2010/295394.

3. Combs TP, Nagajyothi, Mukherjee S, de Almeida CJ, Jelicks LA, Schubert W, Lin Y, Jayabalan DS, Zhao D, Braunstein VL, Landskroner-Eiger S, Cordero A, Factor SM, Weiss LM, Lisanti MP, Tanowitz HB, Scherer PE: The adipocyte as an important target cell for Trypanosoma cruzi infection. J Biol Chem 2005, 280:24085-24094.

4. Viotti R, Vigliano C, Lococo B, Bertocchi G, Petti M, Alvarez MG, Postan M, Armenti A: Long-term cardiac outcomes of treating chronic Chagas disease with benznidazole versus no treatment: a nonrandomized trial. Ann Intern Med 2006, 144:724-734.

5. Nagajyothi F, Machado FS, Burleigh BA, Jelicks LA, Scherer PE, Mukherjee $S$, Lisanti MP, Weiss LM, Garg NJ, Tanowitz HB: Mechanisms of Trypanosoma cruzi persistence in Chagas disease. Cell Microbiol 2012, 14:634-643.

6. Soeiro MN, de Castro SL: Screening of potential anti-trypanosoma cruzi candidates: In vitro and In vivo studies. Open Med Chem J 2011, 5:21-30.

7. Souza RA, Henriques C, Alves-Ferreira M, Mendonça-Lima L, Degrave WM: Investigation of a protein expression profile by high-resolution bidimensional electrophoresis of Trypanosoma cruzi epimastigotes. Anal Biochem 2007, 365:144-146.

8. Ferella M, Nilsson D, Darban H, Rodrigues C, Bontempi EJ, Docampo R, Andersson B: Proteomics in Trypanosoma cruzi-localization of novel proteins to various organelles. Proteomics 2008, 8:2735-2749.

9. Alves-Ferreira M, Guimarães AC, Capriles PV, Dardenne LE, Degrave WM: A new approach for potential drug target discovery through in silico metabolic pathway analysis using Trypanosoma cruzi genome information. Mem Inst Oswaldo Cruz 2009, 2009(104):1100-1110.

10. Henriques C, Moreira TLB, Maia-Brigagão C, Henriques-Pons A, Carvalho TMU, de Souza W: Tetrazolium salt based methods for high-throughput evaluation of anti-parasite chemotherapy. Anal Methods 2011, 3:2148-2155.

11. Andriani G, Chessler AD, Courtemanche G, Burleigh BA, Rodriguez A: Activity in vivo of anti-Trypanosoma cruzi compounds selected from a high throughput screening. PLoS Negl Trop Dis 2011, 5:e1298.

12. Henriques C, Castro DP, Gomes LH, Garcia ES, de Souza W: Bioluminescent imaging of Trypanosoma cruzi infection in Rhodnius prolixus. Parasit Vectors 2012, 5:214

13. Thalhofer CJ, Graff JW, Love-Homan L, Hickerson SM, Craft N, Beverley SM, Wilson ME: In vivo imaging of Transgenic leishmania parasites in a live host. J Vis Exp 2010, 41:e1980

14. Saeij JP, Boyle JP, Grigg ME, Arrizabalaga G, Boothroyd JC: Bioluminescence imaging of Toxoplasma gondii infection in living mice reveals dramatic differences between strains. Infect Immun 2005, 73:695-702.

15. Camargo EP: Growth and differentiation in Trypanosoma cruzi. Rev Inst Med São Paulo 1964, 6:93-100.

16. Contreras VT, Salles JM, Thomas N, Morel CM, Goldenberg S: In vitro differentiation of Trypanosoma cruzi under chemically defined conditions. Mol Biochem Parasitol 1985, 16:315-327.

17. Brener $Z$ : Therapeutic activity and criterion of cure in mice experimentally infected with Trypanosoma cruzi. Rev Inst Med Trop Sao Paulo 1962, 4:389-396.

18. Vazquez MP, Levin MJ: Functional analysis of the intergenic region of TcP2 $\beta$ gene loci allowed the construction of a improved Trypanosoma cruzi expression vector. Gene 1999, 239:217-225.

19. Cruz A, Beverley SM: Gene replacement in parasitic protozoa. Nature 1990, 348:171-173.

20. Andrade SG: Influence of Trypanosoma cruzi strain on the pathogenesis of chronic myocardiopathy in mice. Mem Inst Oswaldo Cruz 1990, 85:17-27.

21. Araújo-Jorge T: (ORG). Doença de Chagas: Manual para experimentação animal. Rio de Janeiro: Editora Fiocruz / Instituto Oswaldo Cruz; 2000:368.

22. Medeiros MM, Araújo-Jorge TC, Batista WS, da Silva TMOA, de Souza AP: Trypanosoma cruzi infection: do distinct populations cause intestinal motility alteration? Parasitol Res 2010, 107:239-242.

23. Calvet CM, Meuser M, Almeida D, Meirelles MN, Pereira MC: Trypanosoma cruzi-cardiomyocyte interaction: role of fibronectin in the recognition process and extracellular matrix expression in vitro and in vivo. Exp Parasitol 2004, 107:20-30.

24. Gutierrez FR, Mineo TW, Pavanelli WR, Guedes PM, Silva JS: The effects of nitric oxide on the immune system during Trypanosoma cruzi infection. Mem Inst Oswaldo Cruz 2009, 104:236-245

25. Arantes RM, Marche HH, Bahia MT, Cunha FQ, Rossi MA, Silva JS: Interferongamma-induced nitric oxide causes intrinsic intestinal denervation in Trypanosoma cruzi-infected mice. Am J Pathol 2004, 164:1361-1368.

26. Steindel M, Scholz AF, Toma HK, Schlemper BR Jr: Presence of Trypanosoma cruzi in the anal glands of naturally infected opossum (didelphis Marsupialis) in the state of Santa Catarina Brazil. Mem Inst Oswaldo Cruz 1988, 83:135-137.

27. Andrade LO, Galvão LM, Meirelles Mde N, Chiari E, Pena SD, Macedo AM Differential tissue tropism of Trypanosoma cruzi strains: an in vitro study. Mem Inst Oswaldo Cruz 2010, 105:834-837. 
28. Espinoza B, Rico T, Sosa S, Oaxaca E, Vizcaino-Castillo A, Caballero ML, Martínez I: Mexican Trypanosoma cruzi T. cruzi I strains with different degrees of virulence induce diverse humoral and cellular immune responses in a murine experimental infection model. J Biomed Biotechnol 2010, 2010:890672. doi: 10.1155/2010/890672.

29. Hyland KV, Asfaw SH, Olson CL, Daniels MD, Engman DM: Bioluminescent imaging of Trypanosoma cruzi infection. Int J Parasitol 2008, 38(12):1391-1400.

30. Canavaci AMC, Bustamante JM, Padilla AM, Perez Brandan CM, Simpson LJ, $\mathrm{Xu}$ D, Boehlke $\mathrm{CL}$, Tarleton RL: In vitro and in vivo high-throughput assays for the testing of anti-Trypanosoma cruzi compounds. PLoS Neglected Trop Disease 2010, 4:e740.

31. Zingales B, Andrade SG, Briones MR, Campbell DA, Chiari E, Fernandes O, Guhl F, Lages-Silva E, Macedo AM, Machado CR, Miles MA, Romanha AJ, Sturm NR, Tibayrenc M, Schijman AG: A new consensus for Trypanosoma cruzi intraspecific nomenclature: second revision meeting recommends Tcl to TcVI. Mem Inst Oswaldo Cruz 2009, 104:1051-1054.

32. Higuera SL, Guhl F, Ramírez JD: Identification of Trypanosoma cruzi Discrete Typing Units (DTUs) through the implementation of High-Resolution Melting (HRM) genotyping assay. Parasit Vectors 2013, 6:112.

33. Black CL, Ocanã S, Riner D, Costales JA, Lascano MS, Davila S, Arcos-Teran L, Seed JR, Grijalva MJ: Household risk factors for Trypanosoma cruzi seropositivity in two geographic regions of Ecuador. J Parasitol 2007, 93:12-16.

34. Mejía-Jaramillo AM, Penã VH, Triana-Chávez O: Trypanosoma cruzi: biological characterization of lineages I and II supports the predominance of lineage I in Colombia. Exp Parasitol 2009, 121:83-91.

35. Carrasco HJ, Segovia M, Llewellyn MS, Morocoima A, Urdaneta-Morales S, Martínez C, Martínez CE, Garcia C, Rodríguez M, Espinosa R, de Noya BA, Díaz-Bello Z, Herrera L, Fitzpatrick S, Yeo M, Miles MA, Feliciangeli MD: Geographical distribution of Trypanosoma cruzi genotypes in Venezuela. PLoS Negl Trop Dis 2012, 6:e1707.

doi:10.1186/1756-3305-7-89

Cite this article as: Henriques et al: In vivo imaging of mice infected with bioluminescent Trypanosoma cruzi unveils novel sites of infection. Parasites \& Vectors 2014 7:89.

\section{Submit your next manuscript to BioMed Central and take full advantage of:}

- Convenient online submission

- Thorough peer review

- No space constraints or color figure charges

- Immediate publication on acceptance

- Inclusion in PubMed, CAS, Scopus and Google Scholar

- Research which is freely available for redistribution 